\title{
Low-Efficiency of Percutaneous Adenovirus-mediated Arterial Gene Transfer in the Atherosclerotic Rabbit
}

\author{
Laurent J. Feldman, P. Gabriel Steg, * Lu P. Zheng, Dongfen Chen, Marianne Kearney, Sean E. McGarr, James J. Barry, \\ Jean-François Dedieu, $\mathbf{5}$ Michel Perricaudet, $\mathbf{5}$ and Jeffrey $\mathbf{M}$. Isner \\ Departments of Medicine (Cardiology) and Biomedical Research, St. Elizabeth's Medical Center, Tufts University School of Medicine, \\ Boston, Massachusetts, 02135; *Unité Physiopathologie du Coeur et des Artères, Faculté Bichat, Paris, France; ${ }^{\ddagger}$ Boston Scientific \\ Corporation, Watertown, Massachusetts; and ${ }^{8}$ UA 1301 CNRS, Institut Gustave Roussy, Villejuif, France
}

\begin{abstract}
Recombinant adenoviruses are the most efficient vectors with which to perform arterial gene transfer. Previous in vivo studies of adenovirus-mediated arterial transfection, however, have been performed using normal or endothelium-denuded arteries. It is unclear whether these results can be extended to atherosclerotic arteries. Accordingly, this study was designed to $(a)$ assess the feasibility of adenovirusmediated gene transfer to atherosclerotic lesions, and (b) compare the transfection efficiency, anatomic distribution of transfected cells, and duration of transgene expression achieved in normal versus atherosclerotic arteries. A recombinant adenovirus including a nuclear-targeted $\beta$-galactosidase gene was percutaneously delivered to the iliac artery of normal $(n=25)$ and atherosclerotic $(n=25)$ rabbits. Transgene expression, assessed by morphometric as well as chemiluminescent analyses, was documented in all normal and atherosclerotic arteries between 3 and $14 \mathrm{~d}$ after gene transfer, but was undetectable at later time points. Transfected cells were identified as smooth muscle cells located in the media of normal arteries, and in the neointima and the vasa-vasora of atherosclerotic arteries. Two percent of medial cells, but only $0.2 \%$ of medial and neointimal cells expressed the transgene in normal and atherosclerotic arteries, respectively $(P=\mathbf{0 . 0 0 0 1})$. Similarly, nuclear $\beta$-galactosidase activity was higher in normal than in atherosclerotic arteries (3.2 vs. $0.8 \mathrm{mU} / \mathrm{mg}$ protein, $P=0.02)$. These findings indicate that atherosclerosis reduces the transfection efficiency which can be achieved with adenoviral vectors, and thus constitutes a potential limitation to adenovirus-based, arterial gene therapy. (J. Clin. Invest. 1995. 95:2662-2671.) Key words: adenovirus • transfection • gene expression $\bullet$ atherosclerosis $\bullet \boldsymbol{\beta}$-galactosidase
\end{abstract}

\section{Introduction}

Replication defective, recombinant adenoviruses are efficient vectors for in vivo arterial gene transfer $(1-10)$. In a few studies,

This work was presented in part at the 67th Annual Scientific Sessions of the American Heart Association, Dallas, TX, November 14-17, 1994. Address correspondence to Jeffrey M. Isner, M.D., St. Elizabeth's Medical Center, 736 Cambridge Street, Boston, MA 02135. Phone: 617789-2392; FAX: 617-789-5029.

Received for publication 6 December 1994.

J. Clin. Invest.

(c) The American Society for Clinical Investigation, Inc.

$0021-9738 / 95 / 06 / 2662 / 10 \$ 2.00$

Volume 95, June 1995, 2662-2671 the transgene, inserted into the adenoviral genome, has been successfully delivered to the arterial wall using a percutaneous approach similar to the procedure used to perform coronary angioplasty $(4,5,7,9,10)$. Despite the variation in catheter designs used, the resulting transfection efficiencies have been typically higher than those achieved with retroviral vectors $(11$, 12) plasmid DNA/liposome complexes $(11,13,14)$, or plasmid DNA alone $(15,16)$. It is unclear, however, whether these results, obtained in normal or endothelium-denuded arteries, can be extended to more extensively diseased arteries (17). This issue is relevant to clinical applications of arterial gene transfer, such as prevention of restenosis or therapeutic angiogenesis, which would more typically require efficient transfection of atherosclerotic arteries. Certain pathologic characteristics of human atherosclerosis can be mimicked in the rabbit iliac artery by the combination of a hypercholesterolemic diet and balloon injury (18-20). Accordingly, this model was used in the present study to: $(a)$ investigate the feasibility of percutaneous, adenovirus-mediated gene transfer to atherosclerotic lesions; and (b) compare the transfection efficiency, anatomic distribution of transfected cells, and duration of transgene expression achieved in normal versus atherosclerotic arteries.

\section{Methods}

\section{Recombinant adenoviruses}

Replication-defective, recombinant adenoviruses based on human adenovirus 5 serotype were constructed, grown, and purified as previously described (21-23). Ad-RSV $\beta$ gal contains a deletion of E1a and part of E1b and E3 regions of the adenoviral genome, and includes an expression cassette for a variant of Escherichia coli $\beta$-galactosidase gene (nlslacZ), encoding a nuclear-targeted $\beta$-galactosidase under the control of the Rous sarcoma virus long terminal repeat promoter. Ad-RSVapoAl (courtesy of Dr. Patrick Benoit, Rhône-Poulenc-Rorer, Vitry, France) contains an apolipoprotein Al gene under the control of the same promoter. Each adenovirus preparation was tittered by plaqueassay on 293 cells. Viral stocks $\left(10^{11}\right.$ plaque forming units [pfu] $\left./ \mathrm{ml}\right)$ were stored at $-80^{\circ} \mathrm{C}$ and thawed on ice for $5 \mathrm{~min}$ before use.

\section{Arterial gene transfer in vivo}

New-Zealand white rabbits (weight 4.0-4.5 kg), either normal $(n=25)$ or hypercholesterolemic $(n=25)$, were used in this study. Animal protocols were approved by St. Elizabeth's Medical Center Institutional Animal Care and Use Committee. Hypercholesterolemic rabbits were fed a $1 \%$ cholesterol diet for $7 \mathrm{wk}$ before gene transfer. This diet resulted in high cholesterol levels at the time of transfection $(1453 \pm 38 \mathrm{mg} / \mathrm{dl})$, consistent with previous reports (18). 1 wk after initiation of the diet, focal lesions were induced in both iliac arteries, by balloon de-endothelialization using three passes of a 4F Swan-Ganz balloon catheter introduced through the left carotid artery (adapted from Baumgartner et al. [24], Leclerc et al. [14], and Weidinger et al. [20]). 
A

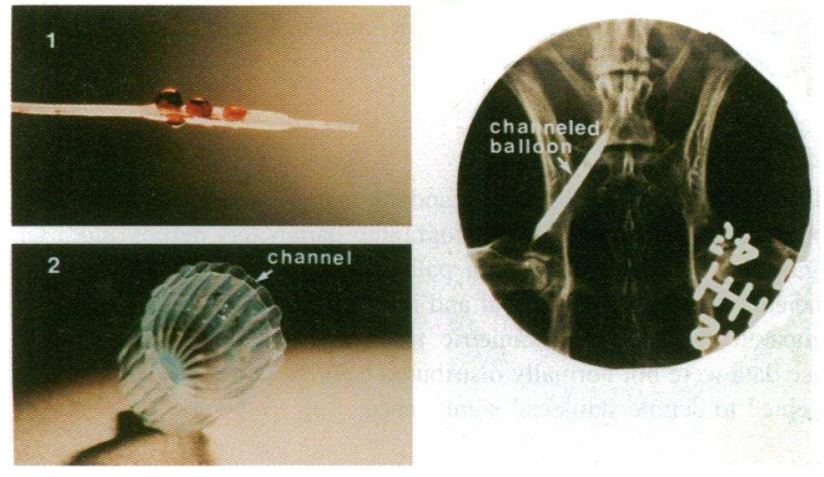

Figure 1. The channeled-balloon angioplasty catheter. $(A)$ Longitudinal (1) and cross-sectional (2) views of the channeled-balloon. Adenoviral solutions are infused through small perforated channels which are located on the surface of the angioplasty balloon. Pressures for balloon inflation and adenovirus infusion can thus be separated. (B) Radiograph showing the channeled-balloon inflated in a normal external iliac artery. Balloon-angioplasty and transfection are performed simultaneously. Infusion of contrast medium into the balloon inflation lumen delineates balloon contour.

In vivo gene transfer was performed under general anesthesia induced by intra-muscular injection of ketamine $(50 \mathrm{mg} / \mathrm{kg})$ and xylazine $(10 \mathrm{mg} / \mathrm{kg})$. The local delivery device used in these experiments was a channeled-balloon angioplasty catheter (Mansfield Medical, Boston Scientific Corp., Watertown, MA). This catheter incorporates a conventional, 20-mm-long polyethylene teraphalate balloon covered by a layer of 24 perforated channels which are perfused via an independent lumen (Fig. 1). This design is intended to permit low-pressure, local drug delivery simultaneous with high-pressure balloon angioplasty (25). Balloon diameter was chosen to approximate a 1.0:1.0 balloon/artery ratio based on caliper measurement of magnified angiographic frames.

The catheter was introduced through the right carotid artery over a 0.014 inch guide-wire and advanced into the abdominal aorta. In atherosclerotic rabbits, arterial blood was drawn for determination of total serum cholesterol, and an aorto-iliac angiogram was obtained before gene transfer. The catheter was then advanced into the right external iliac artery, and inflated at nominal pressure $(8 \mathrm{~atm})$ immediately distal to the bifurcation between the external and internal iliac arteries. One $\mathrm{ml}$ of viral solution ( $4.10^{9} \mathrm{pfu}$ of Ad-RSV $\beta$ gal in saline) was instilled through the infusion port of the catheter under 2 atm pressure using a $10 \mathrm{ml}$ LeVeen Inflator (Medi-Tech, Boston Scientific Corp., Watertown, MA). Infusion time ranged from 90 to $150 \mathrm{~s}$. The infusion pressure was chosen to avoid deep arterial injury $(7,12)$ and adenovirus dissemination (7) reportedly induced by higher delivery pressure using a porous-balloon system. After $30 \mathrm{~min}$ of incubation, the balloon was deflated, a posttransfection angiogram was obtained in atherosclerotic rabbits, and the catheter was removed. The contralateral iliac artery was used as a control: in both the normal as well as the atherosclerotic rabbits, no catheter or virus was introduced in 15 animals, while in the 10 others a channeled-balloon was inflated, and saline $(n=5)$ or Ad-RSVapoA1 $\left(4.10^{9} \mathrm{pfu}\right.$ in $1 \mathrm{ml}$ saline, $\left.n=5\right)$ instilled as previously described.

\section{Quantitative angiography}

In 10 atherosclerotic rabbits, quantitative analysis of angiograms of the transfected arteries obtained before and after transfection/angioplasty was performed using a computerized arterial analysis system (ImageComm, Inc., Santa Clara, CA), as previously described (26). Luminal narrowing, expressed as percent stenosis, was determined by comparison with the largest lumen diameter distal to the lesion. The transfected segment was analyzed for percent luminal narrowing at the site of most severe focal stenosis, as well as for mean percent luminal narrowing along the entire length of the transfected segment.

\section{Digital planimetry of atherosclerotic lesions}

In four atherosclerotic rabbits sacrificed $3 \mathrm{~d}$ after gene transfer, eight arterial sections were taken from uninstrumented control arteries harvested as described below, and analyzed by digital planimetry using a computer-assisted morphometric program (MACMEASURE 1.9, Apple) and a graphics digitizing table (SUMMASKETCH; Summagraphics Corp., Austin, TX). The luminal area, as well as the areas bounded by both the internal and external elastic laminae were measured. The neointimal area was calculated by subtraction of the lumen area from the area bounded by the internal elastic lamina. Two indexes of lesion formation were calculated: $(a)$ the ratio of the neointimal to medial area (neointima/media ratio), and $(b)$ the ratio of the neointimal area to the area bounded by the internal elastic lamina (luminal crosssectional area narrowing).

\section{Transfection efficiency $3 d$ after gene transfer}

$3 \mathrm{~d}$ after gene transfer, 17 normal and 17 atherosclerotic rabbits were killed by pentobarbital overdose. In each group, transfection efficiency was determined by morphometric $(n=10)$ and chemiluminescent $(n$ =7) analyses.

Morphometric analyses. Both iliac arteries were perfusion-fixed with $1 \%$ paraformaldehyde, harvested, and incubated with the same fixative for an additional $5 \mathrm{~min}$. $\beta$-galactosidase activity was assessed by incubating arteries in X-GAL chromogen (Boehringer Mannheim Corp., Indianapolis, $\mathrm{IN})$ for $2 \mathrm{~h}$ at $37^{\circ} \mathrm{C}$, as previously reported $(2,9,27)$. This short incubation time was used to avoid detection of nonspecific endogenous $\beta$-galactosidase activity. After staining, arteries were rinsed in saline, post-fixed in $1 \%$ paraformaldehyde, and photographed through a dissecting microscope. A 2-cm-long arterial segment, immediately distal to the internal iliac artery, was sectioned into four serial 5-mmlong rings. The rings were subsequently embedded in paraffin, and twelve $6-\mu \mathrm{m}$-thick sections were cut from each ring at six different levels throughout the entire length of the ring. Arterial sections were counterstained with hematoxylin and eosin or Richardson's elastic-trichrome and examined through a light microscope. Expression of transfected nlslac $Z$ gene was considered positive only when dark blue nuclear staining was observed.

In both normal and hypercholesterolemic rabbits, 40 arterial rings, representing 480 arterial sections, and more than 500,000 cells were evaluated for transgene expression. In each ring, $\beta$-galactosidase activity was assessed on gross examination using a 4-grade semi-quantitative score $(0,1,2,3$ : no, low, intermediate, high $\beta$-galactosidase activity, respectively). In each arterial section, transfection efficiency was determined as $(a)$ the percentage of stained versus total medial and neointimal cells per arterial section; and $(b)$ the absolute number of stained medial and neointimal cells per arterial section.

Chemiluminescent assay. Nuclear extracts were prepared from both iliac arteries as described by Schreiber et al (28). Briefly, arteries were homogenized immediately after sacrifice in ice-cold lysis buffer $(10$ mM Hepes pH 7.9, $10 \mathrm{mM} \mathrm{KCl,} 0.1 \mathrm{mM}$ EDTA, $0.1 \mathrm{mM}$ EGTA, 1 $\mathrm{mM}$ DTT, $0.5 \mathrm{mM}$ PMSF). The homogenate was incubated on ice for $15 \mathrm{~min}$, then centrifuged for $30 \mathrm{~s}$ in a microfuge. The nuclear pellet was resuspended in ice-cold hyperosmolar buffer $(20 \mathrm{mM}$ Hepes $\mathrm{pH}$ 7.9, $0.4 \mathrm{M} \mathrm{NaCl}, 1 \mathrm{mM}$ EDTA, $1 \mathrm{mM}$ EGTA, 1 mM DTT, 1 mM PMSF), incubated for $15 \mathrm{~min}$ at $4^{\circ} \mathrm{C}$ on a shaking platform, then centrifuged for $5 \mathrm{~min}$. The supernatant (nuclear extract) was stored at $-80^{\circ} \mathrm{C}$ until use.

$\beta$-galactosidase activity in the nuclear extract was measured using a chemiluminescent assay (GALACTO-LIGHT; Tropix Inc., Bedford, MA) and a LUMAT luminometer (Berthold, Nashua, $\mathrm{NH}$ ) as previously described (2). The assay background was determined with the hyperosmolar buffer used for nuclear extraction. The assay was calibrated with a standard curve generated by using purified Escherichia coli $\beta$-galactosidase (Boehringer Mannheim, specific activity $300 \mathrm{U} / \mathrm{mg}$ ). The calibration curve was linear from 7.5 to $7500 \mu \mathrm{U}$ of $\beta$-galactosidase. When 
light emission was below that produced by $7.5 \mu \mathrm{U}, \beta$-galactosidase activity was arbitrarily considered undetectable. All reactions were done in duplicate on 1- and 2-fold dilutions of the nuclear extract. The mean of the two values was used to measure total nuclear $\beta$-galactosidase activity per vessel. Protein content in the nuclear extract was measured using the BIO-RAD protein assay (Bio-Rad, Hercules, CA). Transfection efficiency was expressed as $(a)$ nuclear $\beta$-galactosidase activity normalized to the nuclear protein content; and $(b)$ total nuclear $\beta$-galactosidase activity per vessel.

\section{Immunohistochemistry}

To determine which cell types within the arterial wall expressed the transgene, immunohistochemical staining of X-gal-stained arterial sections was performed using, as a primary antibody, a mouse monoclonal antibody specific for either smooth muscle $\alpha$-actin (HHF-35; Enzo Diagnostics, Farmingdale, NY), or macrophages (RAM-11; Dako, Carpintiera, CA), and then a polyclonal peroxidase-labeled (Signet Laboratories, Dedham, MA) or alkaline phosphatase-labeled (Biogenex, San Ramon, CA) anti-mouse immunoglobulin G secondary antibody.

\section{Duration of transgene expression}

To compare the duration as well as the kinetics of transgene expression in normal and atherosclerotic arteries, additional normal $(n=8)$ and atherosclerotic $(n=8)$ rabbits were included in a time-course study. In these animals, $\beta$-galactosidase activity was measured in nuclear extracts from transfected arteries harvested 3, 7, 14, and $21 \mathrm{~d}$ after gene transfer ( $n=2$ in each group and at each time-point), using the chemiluminescent assay described above.

\section{Detection of extra-arterial transfection}

In five normal and five atherosclerotic rabbits sacrificed $3 \mathrm{~d}$ after transfection, tissue samples from liver, brain, testes, lung, myocardium, kidney, and right limb skeletal muscle ipsilateral to the transfected artery were harvested immediately after sacrifice. For each specimen, nlslacZ gene presence and expression were assessed by optimized polymerase chain reaction (PCR) and histochemical staining (X-gal), respectively.

PCR protocol. DNA was extracted from tissues by standard techniques. DNA amplification was carried out in presence of ${ }^{32} \mathrm{P}$-radiolabeled dCTP using oligonucleotide primers designed to selectively amplify Ad-RSV $\beta$ gal DNA over the endogenous $\beta$-galactosidase gene by placing one primer in the adenovirus sequence coding for protein 9 and the other primer in the nlslacZ sequence as previously described (9). Amplification products were detected on $1 \%$ agarose gel stained with ethidium bromide as well as by autoradiography. When PCR was performed on the recombinant plasmid pAd-RSV $\beta$ gal used for the preparation of Ad-RSV $\beta$ gal (22), the amplification reaction yielded a 700-bp fragment. To determine the sensitivity of the amplification protocol, DNA was extracted from liver of non-transfected rabbits and mixed with serial dilutions of pAd-RSV $\beta$ gal. It was determined that the PCR could detect one copy of the Ad-RSV $\beta$ gal genome in $3.10^{4}$ cells.

Histochemistry. Each tissue specimen was also processed for histochemical analysis following the same protocol described for the arteries. For each specimen, two samples $(\sim 300 \mathrm{mg} / \mathrm{sample})$ were obtained, embedded in paraffin, and cut into six $6-\mu$ m-thick sections, at three different levels. Sections were counterstained with hematoxylin and eosin, and examined by light microscopy for the presence of dark blue nuclei indicative of nlslacZ gene expression. In each organ, between $15.10^{3}$ and $150.10^{3}$ cells were examined.

\section{Summary of transfection experiments}

A total of 25 normal and 25 atherosclerotic rabbits were studied. In each group, the right iliac artery was transfected with the Ad-RSV $\beta$ gal vector, and the left iliac artery served as the control (uninstrumented, $n=15$; transfected with the control vector Ad-RSVapoA1, $n=5$; sham-transfected with saline alone, $n=5$ ). In each group, transfection efficiency was measured $3 \mathrm{~d}$ after gene transfer in 17 rabbits by morphometric $(n=10)$ and chemiluminescent $(n=7)$ analyses. In 10 of these animals (normal, $n=5$; atherosclerotic, $n=5$ ), extra-arterial transfection was investigated. The time-course of transgene expression was studied in 16 additional rabbits (normal, $n=8$; atherosclerotic, $n$ $=8$ ).

\section{Statistical analyses}

Values are expressed as mean \pm standard error of the mean $(m \pm S E M)$. Comparisons of quantitative angiographic parameters before and after angioplasty were made using a paired Student's $t$ test. Transfection efficiencies achieved in normal and hypercholesterolemic rabbits were compared using a non-parametric test (Mann-Whitney U-test) since these data were not normally distributed (29). A value of $P<0.05$ was accepted to denote statistical significance.

\section{Results}

\section{Quantitative angiographic analyses}

In atherosclerotic rabbits, balloon angioplasty performed at the time of transfection resulted in significant reduction of maximal and mean luminal diameter narrowing from $63.5 \pm 2.6 \%$ to $33.2 \pm 2.1 \%(P<0.001)$, and from $33.8 \pm 2.7 \%$ to $27.3 \pm 2.9 \%$ $(P=0.02)$, respectively.

\section{Planimetry of atherosclerotic lesions}

Intimal thickening covered $100 \%$ of the circumference of the arterial lumen in each case. Neointima/media ratio and crosssectional area narrowing averaged $1.7 \pm 0.1$ (range 1.3-2.3) and $65.2 \pm 4.0 \%$ (range 40.0-80.5), respectively.

\section{Histological and histochemical analyses of transfected arteries $3 d$ after gene transfer}

Normal arteries (Fig. 2). Transfection was successful in all normal arteries (10/10). Gross examination after X-gal staining showed intense blue staining over the entire length of the luminal aspect of the angioplasty site (Fig. $2 A$ ). In one rabbit, low $\beta$-galactosidase activity was also found in the common and the internal iliac arteries ipsilateral to the transfected site. Microscopic examination of the transfected sites confirmed consistent endothelium denudation in all cases, while continuity of the internal elastic membrane and the integrity of the underlying tunica media were consistently preserved (Fig. $2 E$ ). Dark blue nuclear staining was present, not only in superficial (Fig. $2 C$ ), but also in deeper cell layers of the media (Fig. $2 D$ ), indicating that these cells had been successfully transfected with the nlslacZ gene. Distribution of transfected cells was heterogeneous, positive regions alternating with negative areas over the entire cross-section. Positive immunohistochemical staining for $\alpha$-actin identified transfected medial cells as vascular smooth muscle cells (Fig. $2 F$ ). $\beta$-galactosidase activity was undetectable in control arteries (Fig. $2 B$ ). No evidence of injury to the arterial wall attributable to the channeled-balloon (e.g., jetinduced macro- or microscopic injury) was observed on gross or light microscopic examination.

Atherosclerotic arteries (Figs. 3 and 4). Gross examination disclosed concentric stenotic lesions. Arterial dissection and plaque fractures were present in 8/10 and 9/10 rabbits, respectively. All arteries (10/10) showed evidence of transgene expression. In contrast with normal arteries, however, $\beta$-galactosidase activity was present only in scattered foci over the neointima (Fig. 3 A). Microscopic examination failed to detect $\beta$-galactosidase activity in $>40 \%$ of the arterial sections. When present, transgene expression was generally found only in a few cells 

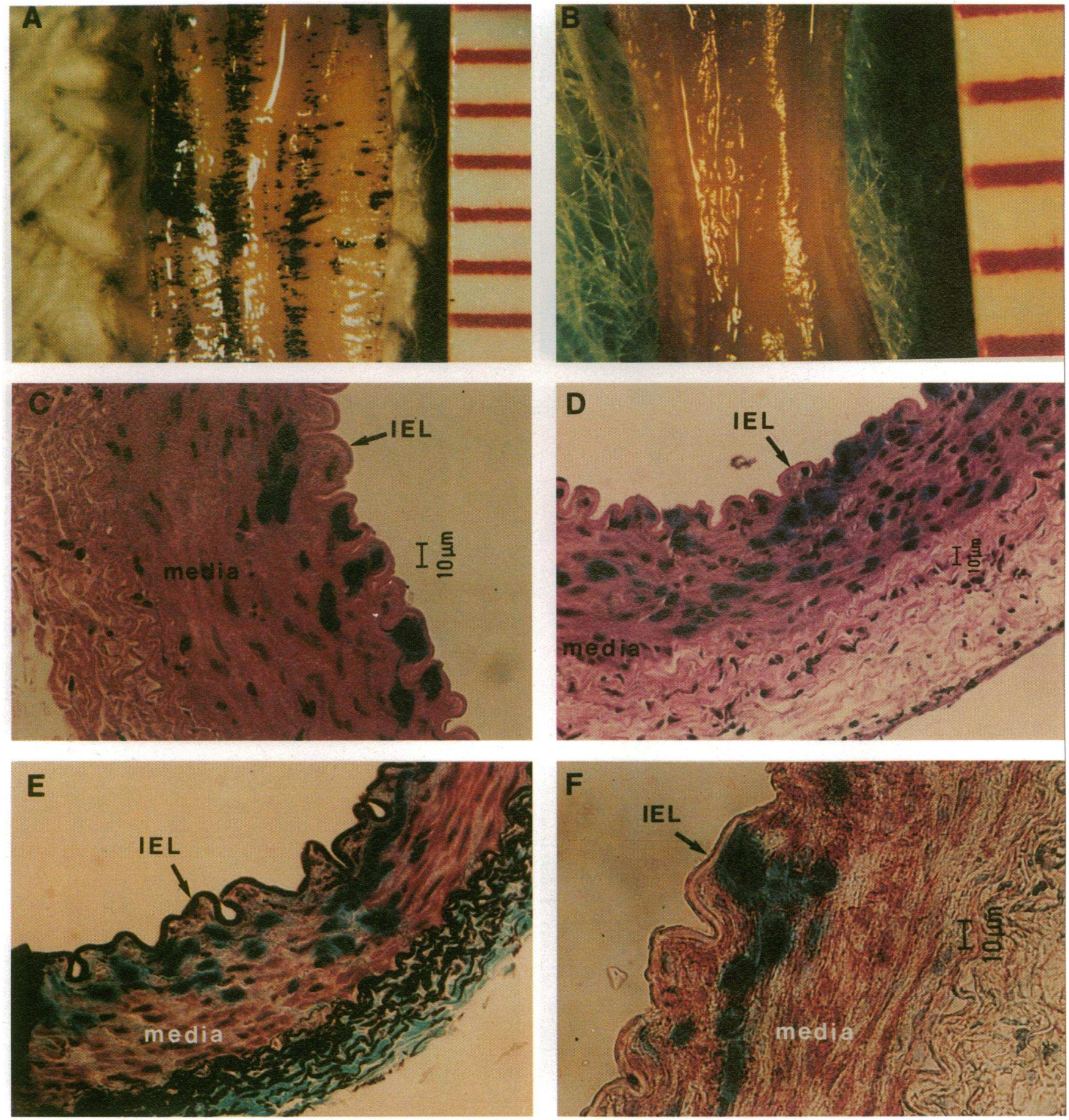

Figure 2. X-gal staining of the iliac arteries of a normal rabbit $3 \mathrm{~d}$ after gene transfer. $(A)$ Macroscopic view of the luminal aspect of the right iliac artery transfected with Ad-RSV $\beta$ gal. Blue staining identifies areas successfully transfected and expressing high levels of $\beta$-galactosidase. $(\times 15)$. (B) Macroscopic view of the luminal aspect of the contralateral artery, transfected with the control adenovirus Ad-RSVapoA1, shows no evidence of $\beta$-galactosidase activity. $(\times 25)$. ( $C$ and $D$ ) Light microscopic appearance of $A$ after hematoxylin-eosin counterstaining. Nuclear-specific blue staining is present in the superficial layers only $(C)$, or in the whole thickness $(D)$ of the media, indicating that these cells have been successfully transfected with the $n l s l a c Z$ gene. IEL, internal elastic lamina. $(E)$ Same as $C$ and $D$ after elastic-trichrome counter-staining. Note that the integrity of the internal elastic lamina (black arrows) is preserved. $(F)$ Same as $C$ and $D$ after immunohistochemical staining with monoclonal anti- $\alpha$-actin antibody. Some superficial medial cells co-express nuclear $\beta$-galactosidase (blue) and cytoplasmic $\alpha$-actin (red), identifying them as vascular smooth muscle cells transfected with the nlslacZ gene.

(less than 10 cells/high power field), located in the superficial layers of the neointima (Fig. $3 \mathrm{C}$ ). The pattern of neointimal transfection, however, was highly variable, with some sections showing higher transfection efficiency (Fig. $3 D$ ). Immunohistochemical staining showed that neointimal lesion consisted of abundant vascular smooth muscle cells, overlying foam-cell 

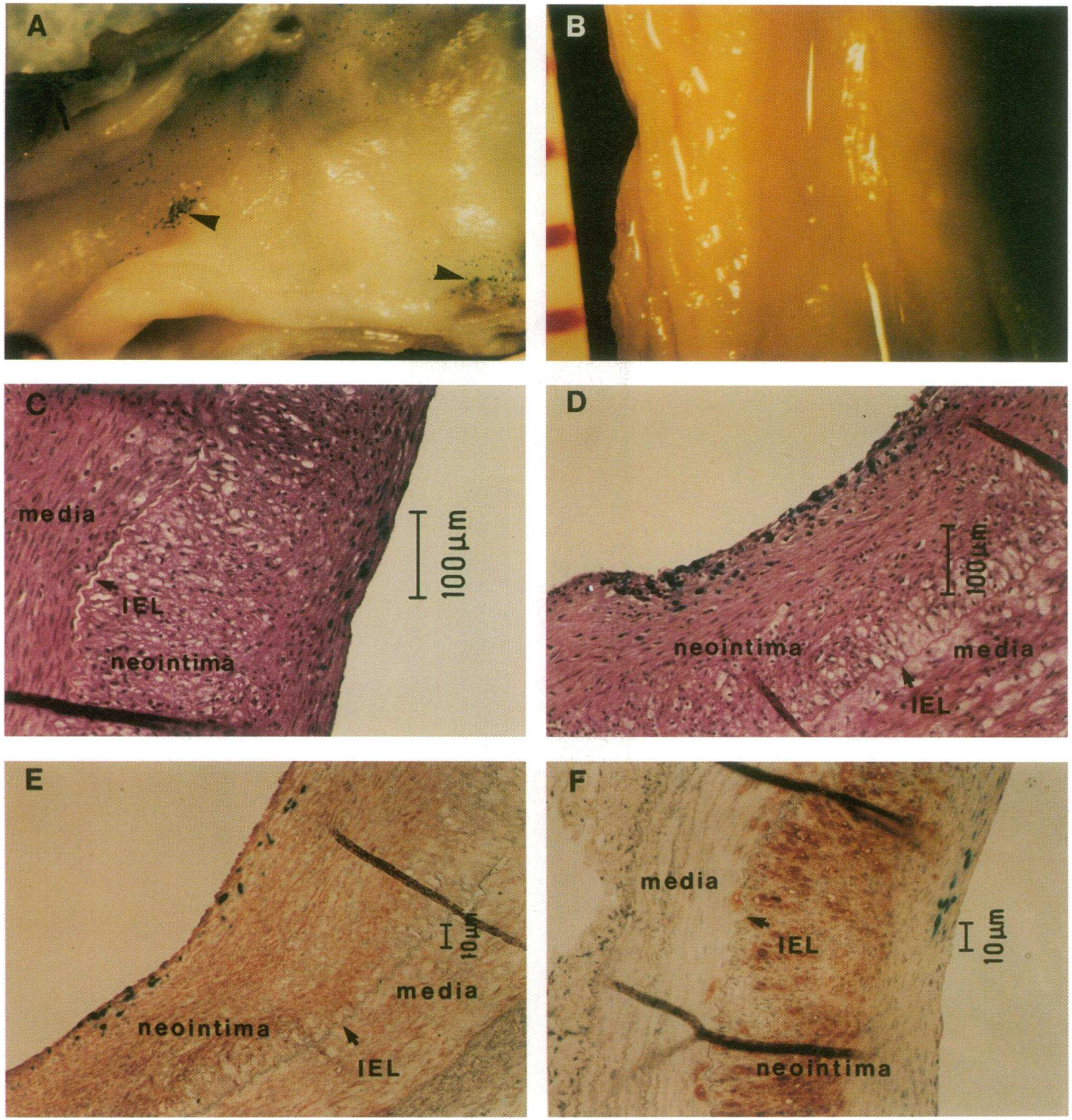

Figure 3. X-gal staining of the iliac arteries of an atherosclerotic rabbit $3 \mathrm{~d}$ after gene transfer. $(A)$ Macroscopic view of the luminal aspect of the right iliac artery transfected with Ad-RSV $\beta$ gal. Diffuse intimal thickening is visible. Low $\beta$-galactosidase activity is present in scattered areas located at the surface of the neointimal lesion (black arrowheads), or in the adventitia (black arrow). $(\times 30)$. (B) Macroscopic view of the luminal aspect of the left iliac artery transfected with Ad-RSVapoA1 shows no detectable $\beta$-galactosidase activity. $(\times 25)$. $(C$ and $D)$ Light microscopic appearance of $A$ after hematoxylin-eosin counterstaining. A well-developed, hypercellular neointimal lesion is present. Nuclear-specific $\beta$-galactosidase activity is present in a small number of superficial neointimal cells $(C)$. Some sections disclose higher transfection efficiency $(D)$. IEL, internal elastic lamina. (E) Same as $C$ and $D$, after immunohistochemical staining for $\alpha$-actin (brown). Note the predominance of smooth muscle cells in the neointimal lesion, and the expected staining of the media. Positive stain for $\alpha$-actin in transfected cells (blue nuclei), identifies these cells as vascular smooth muscle cells. (F) Same as $C$ and $D$ after immunohistochemical staining for macrophages (brown). Macrophage infiltration is found in the outermost layers of the neointima as well as in the media. No positive stain for macrophages is found in transfected cells (blue nuclei). 


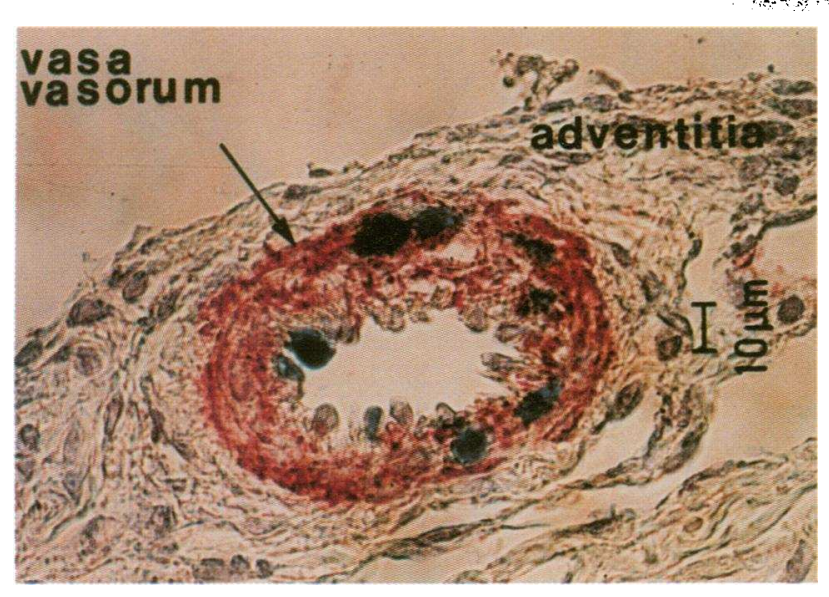

Figure 4. $\alpha$-actin-specific immunohistochemical staining (red) of a vasa-vasorum from an atherosclerotic iliac artery stained with X-gal 3 $\mathrm{d}$ after local delivery of Ad-RSV $\beta$ gal. Note the presence of transfected (dark blue) smooth muscle cells ( $\alpha$-actin-positive) in the vessel wall.

infiltration in the outermost layers of the neointima and in the media (Figs. 3, $E$ and $F$ ), as previously reported $(18,20,30)$. In each case, transfected neointimal cells were identified by immunohistochemistry as vascular smooth muscle cells, whereas no $\beta$-galactosidase activity was found in macrophages (Figs. 3, $E$ and $F$ ). In three arteries, $\beta$-galactosidase activity was also found in the adventitia; in two of these arteries, transgene expression was found in the endothelial and smooth muscle cells of the vasa-vasora (Fig. 4), the probable route for adventitial transfection. No evidence of $\beta$-galactosidase activity was found in control arteries (Fig. $3 \mathrm{~B}$ ).

\section{Transfection efficiency $3 d$ after gene transfer}

Morphometric analysis. Using a semi-quantitative score to approximate regional transfection efficiency on gross examination of arterial rings from transfected arteries, the mean transfection scores were $2.1 \pm 0.2$ and $0.6 \pm 0.1$ in normal ( $n=40$ rings) and atherosclerotic ( $n=40$ rings) arteries, respectively $(P=0.0001)$. Transfection efficiency was also determined quantitatively by counting stained versus total medial and neointimal cells in each arterial section (Fig. 5). In normal arteries ( $n=480$ sections), $2.0 \pm 1.3 \%$ of medial cells (range $0-9.4$ ), representing $23.1 \pm 1.6$ medial cells/arterial section (range 0-113), expressed the transgene. In contrast, in atherosclerotic arteries $(n=480 \mathrm{sec}-$ tions), only $0.2 \pm 0.03 \%$ of medial and neointimal cells (range 0 2.6), representing $4.0 \pm 0.6$ neointimal cells/arterial section (range $0-64$ ), showed evidence of nuclear $\beta$-galactosidase activity. The percentage as well as the absolute number of transfected cells in the neointima and the media were significantly higher in normal than in atherosclerotic arteries $(P=0.0001)$.

Chemiluminescent assay (Fig. 6). Nuclear $\beta$-galactosidase activity was detected in each normal $(n=7)$ as well as atherosclerotic $(n=7)$ artery transfected with the Ad-RSV $\beta$ gal vector. Typically, the level of nuclear $\beta$-galactosidase activity was 20 100 -fold over background. In both groups, light emission generated by nuclear extracts from control arteries in the presence of the chemiluminescent substrate was below that generated by $7.5 \mu \mathrm{U}$ of $\beta$-galactosidase. Therefore, nuclear $\beta$-galactosidase activity in control arteries was considered undetectable. Transfection efficiency was significantly higher in normal than in atherosclerotic arteries when expressed as nuclear $\beta$-galactosidase activity normalized to the nuclear protein content ( $3.2 \mathrm{vs.}$ $0.8 \mathrm{mU} / \mathrm{mg}$ protein, $P=0.02$ ), as well as nuclear $\beta$-galactosidase activity per vessel $(0.70$ vs. $0.20 \mathrm{mU} /$ vessel, $P=0.02)$.

Duration of transgene expression (Fig. 7). A similar pattern was observed in normal and atherosclerotic arteries. Nuclear $\beta$ galactosidase activity peaked at $7 \mathrm{~d}$ after gene transfer then dropped dramatically at $14 \mathrm{~d}$ and was not detectable at $21 \mathrm{~d}$ posttransfection.

Site-specificity of gene transfer. No histochemical evidence of extra-arterial $\beta$-galactosidase activity was found in tissue samples from liver, brain, testes, lung, myocardium, kidney, and skeletal muscle, except in the liver of one normal rabbit, in which less than $1 / 3.10^{3}$ cells expressed the transgene (data not shown). PCR analysis confirmed the presence of the nlslacZ gene in the liver, right limb skeletal muscle, kidney, and lung of the same rabbit, but in no case detected the transgene in organs from the nine other animals (Fig. 8). The rabbit in which remote transfection had occurred was the same animal described above in which transgene expression was found in the internal iliac artery.

\section{Discussion}

The results of this study indicate that: (a) adenovirus-mediated gene transfer to atherosclerotic arteries, although feasible, results in transfection efficiencies which are significantly lower than in normal arteries; (b) transfected cells in atherosclerotic lesions are predominantly smooth muscle cells located in the
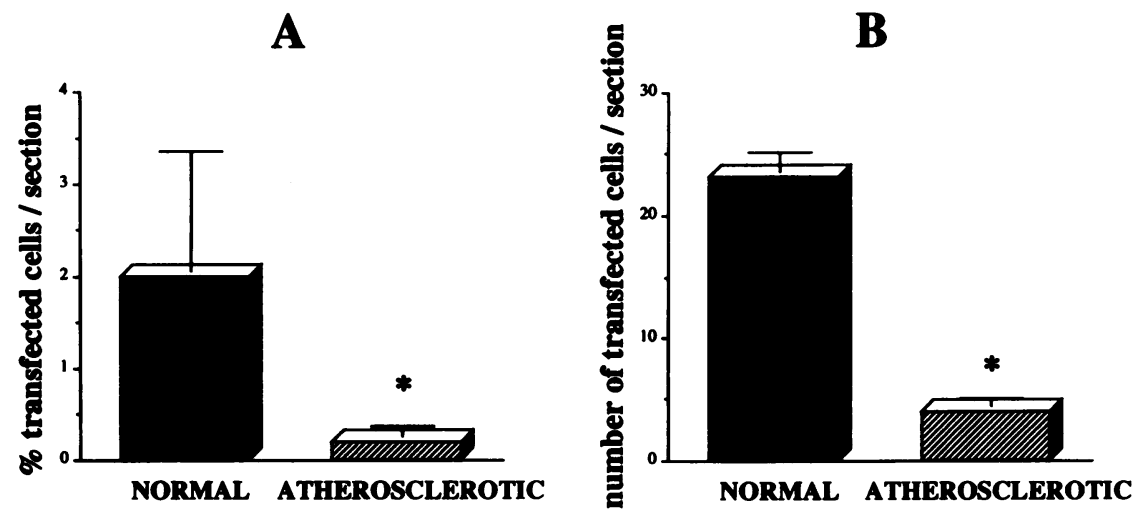

Figure 5. Morphometric analysis of transfection efficiencies achieved in normal and atherosclerotic arteries. Transfection efficiency ( $\mathrm{m} \pm \mathrm{SEM})$, expressed as percent (left) as well as absolute number (right) of transfected medial and neointimal cells/arterial section is higher in normal than in atherosclerotic arteries. Data are the results of 480 determinations from 10 animals in each group. $* P=0.0001$. 

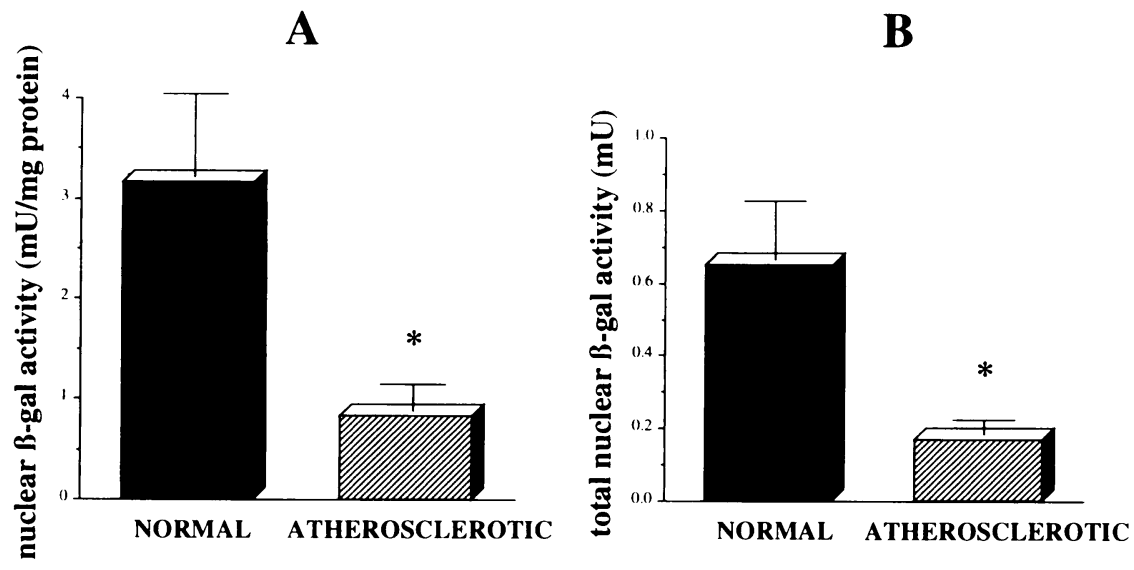

Figure 6. Nuclear $\beta$-galactosidase activity measured in normal and atherosclerotic arteries using the chemiluminescent assay. Transfection efficiency $(\mathrm{m} \pm \mathrm{SEM})$ expressed as nuclear $\beta$-galactosidase activity normalized to nuclear protein content (left) as well as total nuclear $\beta$-galactosidase activity per vessel (right) is higher in normal than in atherosclerotic arteries. Data are the results of seven determinations in each group.

$\beta$-gal, $\beta$-galactosidase; $* P=0.02$.

neointima as well as in the vasa-vasora; $(c)$ duration of transgene expression in atherosclerotic as well as normal arteries is limited to a 2-wk period after gene transfer; and $(d)$ the potential risk of extra-arterial adenovirus distribution is not increased in atherosclerotic arteries as compared with normal arteries.

Adenovirus-mediated, genetic modification of arterial cells has been proposed as a potential strategy to prevent recurrent narrowing (restenosis) following balloon-angioplasty (31). Indeed, Ohno et al recently reported that local delivery of a recombinant adenovirus expressing the herpes virus thymidine kinase at the site of balloon-injury may successfully inhibit smooth muscle cell proliferation and associated neointima formation in the iliac artery of non-atherosclerotic pigs exposed to the nucleoside analog ganciclovir (8). Given that the protein products of genes selected for their anti-proliferative effects typically remain intra-cellular $(8,32,33)$ however, a preemptive strategy

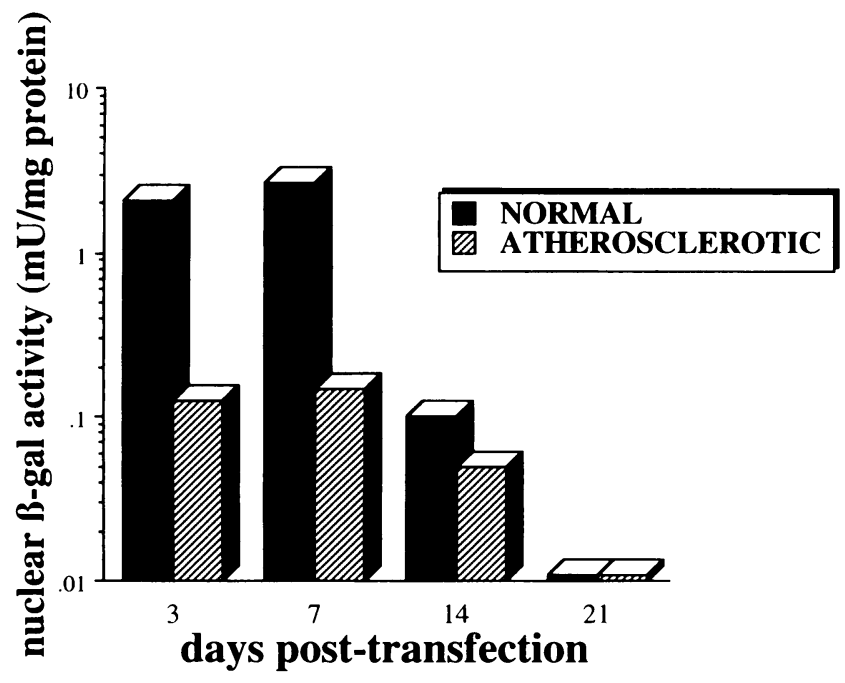

Figure 7. Duration of transgene expression following local delivery of Ad-RSV $\beta$ gal. Transfection efficiency is expressed as nuclear $\beta$-galactosidase activity normalized to nuclear protein content. A similar timecourse is observed in normal and atherosclerotic arteries: nuclear $\beta$ galactosidase activity peaks at $7 \mathrm{~d}$ after gene transfer, then drops dramatically at $14 \mathrm{~d}$ and is undetectable $21 \mathrm{~d}$ posttransfection. Data are the means of two determinations at each time-point in each group. $\beta$-gal, $\beta$-galactosidase. of gene therapy for restenosis will require transduction of a large number of vascular smooth muscle cells at the site of balloon angioplasty (34); this is particularly so for strategies which, unlike thymidine kinase/ganciclovir, are not facilitated by a "bystander effect." The results described here indicate that the number of transduced cells, as well as the enzymatic activity of recombinant protein produced, are lower in atherosclerotic than in normal arteries when adenoviruses are used as vectors for arterial gene transfer; this finding may therefore represent a potential limitation to clinical applications of adenovirus-based arterial gene therapy which involve atherosclerotic vessels.

Two different methods were used in the present study to evaluate transfection efficiency in normal and atherosclerotic arteries. The morphometric analysis provides information on the actual percentage as well as the anatomic distribution of transfected cells. In addition, measurement of $\beta$-galactosidase activity indicates the level of recombinant protein produced. In normal arteries, transfected cells were located in the media and identified as vascular smooth muscle cells; the percentage of transfected medial cells averaged $2 \%$, a result consistent with a previous report of percutaneous, adenovirus-mediated gene transfer to normal arteries (9). In atherosclerotic arteries, transduced cells were identified as smooth muscle cells located predominantly in the superficial layers of the neointima. Adventitial transfection was detected frequently in atherosclerotic but not in normal arteries, and was typically associated with transgene expression in the smooth muscle cells of the vasa-vasora, the probable route for adenovirus distribution to the adventitia. The percentage of transfected neointimal and medial cells, however, was 10-fold lower in atherosclerotic than in normal arteries. The twofold increase in cellularity resulting from neointima formation in atherosclerotic arteries (data not shown), alone, cannot account for this result. Indeed, the absolute number of transfected cells in the media and the neointima of atherosclerotic arteries was 6-fold lower than in the media of normal arteries.

In contrast to the 10 -fold reduction in the percentage of transfected neointimal and medial cells in atherosclerotic arteries, the calculated magnitude of nuclear $\beta$-galactosidase activity was only 3 -fold lower in atherosclerotic than normal arteries. There are two possible explanations for this discrepancy. First, the assay of enzyme activity may simply be more sensitive than histochemical identification of successful cellular transfection. 
A

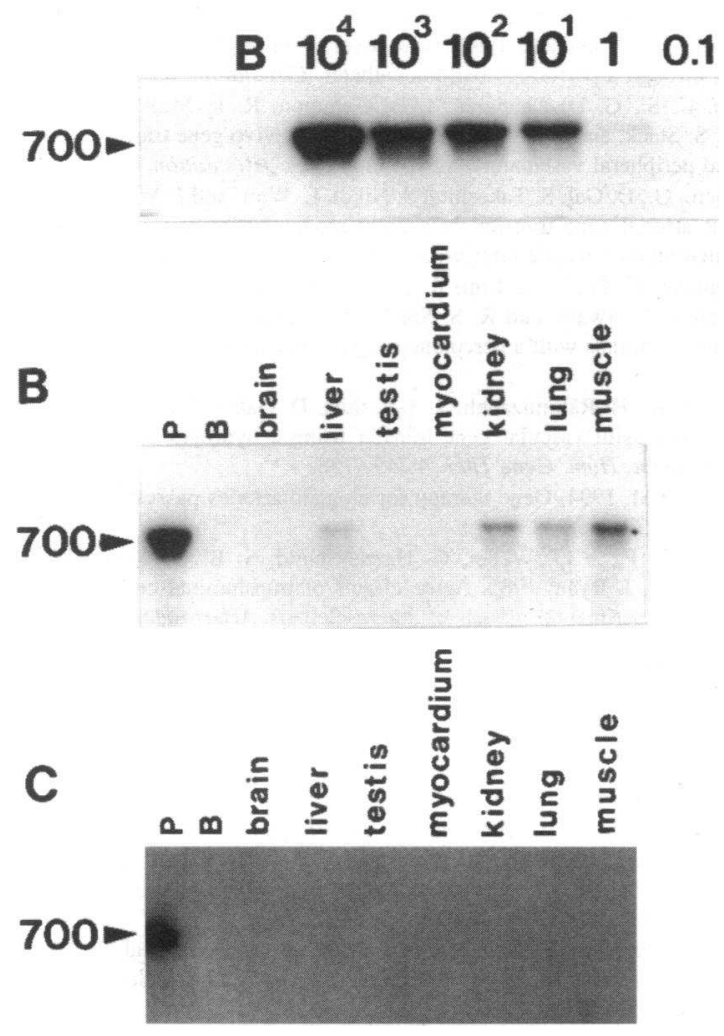

Figure 8. Detection of extra-arterial presence of Ad-RSV $\beta$ gal genome by PCR $3 \mathrm{~d}$ after gene transfer. Amplification products are detected by autoradiography. Molecular mass of the PCR product is indicated in base pairs in the left margin. (A) Sensitivity assay. DNA extracted from the liver of a non-transfected rabbit was spiked with serial dilutions of pAd-RSV $\beta$ gal to approximate ratios of $10^{4}, 10^{3}, 10^{2}, 10,1$, and 0.1 copies of pAd-RSV $\beta$ gal in $3.10^{4}$ cells. As few as 1 copy of pAdRSV $\beta$ gal in $3.10^{4}$ cells could be detected. $B$, blank control (no DNA). ( $B$ and $C$ ) Results of PCR in tissue samples from brain, liver, testis, myocardium, kidney, lung, and skeletal muscle ipsilateral to the transfected site, harvested from two normal rabbits $3 \mathrm{~d}$ after arterial gene transfer. The viral genome is present at low-level in the liver, kidney, lung, and skeletal muscle in one rabbit $(B)$, but is undetectable in tissue samples from the other rabbit $(C) . P$, positive control obtained by amplification of pAd-RSV $\beta$ gal; $B$, blank control (no DNA).

Second, the total nuclear $\beta$-galactosidase activity which was measured for atherosclerotic arteries represents not only neointimal and medial but also adventitial $\beta$-galactosidase activity.

The lower transfection efficiency achieved in atherosclerotic arteries may result from certain topographical and compositional characteristics of the neointimal lesion induced by balloon-injury and hypercholesterolemia. Morphometric and quantitative angiographic analyses showed that intimal thickening covered $100 \%$ of the luminal circumference, resulting in $63.5 \%$ maximal luminal diameter narrowing, $65.2 \%$ cross-sectional area narrowing, and a neointima/media ratio of 1.7. Smooth muscle cells and macrophages account only in part for such a dramatic increase in arterial wall thickness. The connective tissue matrix comprising elastic fiber proteins, collagen, and proteoglycans, as well as accumulated extracellular lipids, contributes significantly to neointima formation in hypercholesterol- emic animals (35). It is thus conceivable that the extracellular matrix may impair adenovirus diffusion within the neointimal lesion and/or the interaction between the adenoviral fiber protein and its receptor on neointimal cells.

The findings of the current study are at odds with conclusions reached by French et al. (10) in a recently published analysis of adenoviral transduction of porcine coronary arteries pre-treated by combinations of cholesterol feeding and arterial injury. They used a porous-balloon catheter to deliver a recombinant adenovirus expressing a luciferase cDNA to porcine coronary arteries, and concluded that ". . . the influence of hypercholesterolemia and arterial injury appeared to have little effect on the levels of gene expression obtained. . . ." Close inspection of their data, however, reveals a nearly fourfold difference between luciferase activity in the arteries of normal versus cholesterol-fed or cholesterol-fed/balloon-injured animals. Interpretation of their findings was complicated by the absence of quantitative or qualitative analysis of the extent to which the transfected arteries were narrowed by atherosclerotic plaque, and the fact that the reporter gene utilized (luciferase) does not easily lend itself to anatomic analyses of the percentage, identity, and transmural distribution of transfected cells, all of which were omitted. The results of the morphometric analysis performed in the present study indicate that the actual percentage of transfected cells in the neointima and the media (as opposed to the adventitia) of atherosclerotic lesions is even lower than might have been predicted by the fourfold decrease in luciferase activity recorded by French et al. The fact that the current study employed a reporter gene which could be readily identified histologically (as well as assayed enzymatically), also permitted us to determine by immunohistochemical staining of adjacent sections that the successfully transfected cell type within the neointimal lesions consisted predominantly of smooth muscle cells, the principal target for gene therapies designed to inhibit restenosis.

The duration of gene expression in the study by French et al. was determined only for normal arteries; despite the apparent reduction in transfection efficiency achieved for atherosclerotic versus normal arteries in the present study, the duration of gene expression we observed for atherosclerotic arteries ( $2 \mathrm{wk}$ ) was similar to that reported by French et al. for normal arteries.

The amphotropic nature of the adenovirus has made it useful for gene transfer strategies in a wide variety of tissue types (21-23, 36-44). Consequently, the capability of preserving site-specific arterial transfection constitutes a relevant consideration for catheter systems designed for local delivery of adenoviral vectors. Moreover, in atherosclerotic arteries, extra-arterial distribution of adenoviruses is more likely to occur via the well developed vasa-vasora (45) and the peri-adventitial tissues. In the current report, however, low-level extra-arterial gene transfer was detected in only one case, that being a normal rabbit. In this one animal, transgene expression was present not only at the transfected site, but also proximally, in the common and internal iliac arteries; the latter were probable routes for extraarterial transfection. In this respect, our findings are consistent with previous observations suggesting that in the absence of extensive angioplasty-induced dissection, adenovirus dissemination is typically undetectable after percutaneous gene transfer to atherosclerotic porcine coronary arteries (10).

Extrapolation of the findings reported here for the neointimal lesion induced by arterial injury in the hypercholesterolemic 
rabbit, to the atherosclerotic lesion responsible for arterial narrowing in humans must be undertaken with some caution. Certain features of advanced primary atherosclerotic lesions in humans are not typical features of lesions generated in this particular animal model. In most cases however, these featuresfibrous cap, calcific deposits, greater proportion of matrix versus cells - might be expected to further compromise adenoviral transduction of atherosclerotic arterial sites. Hence, transfection efficiency in the primary atherosclerotic lesion of humans could be even lower than was observed in the present animal model. Such relatively low transfection efficiency achieved at sites of luminal narrowing may compromise certain clinical applications, particularly those involving genes which encode for proteins which remain intracellular (34). Simple augmentation of the "dose" of vector used may not be the appropriate solution to this problem, in as much as delivery of viral titers $>10^{10}$ $\mathrm{pfu} / \mathrm{ml}$ has been shown to induce cytopathic effects and medial necrosis $(2,46)$. Alternatively, adjunctive means designed to optimize adenovirus-mediated gene transfer, such as the use of polymers (pluronic gel) added to the adenoviral solution (47, 48), warrant further evaluation.

\section{Acknowledgments}

Dr. Feldman is the recipient of an award from the Fulbright Scholar Program. Dr. Isner is supported by grants (HL-40518, HL-02824) from the National Institutes of Health. This work was supported by a grant from Bioavenir (Rhône-Poulenc and French Ministry of Research and Industry).

\section{References}

1. Lemarchand, P., M. Jones, I. Yamada, and R. G. Crystal. 1993. In vivo gene transfer and expression in normal uninjured blood vessels using replicationdeficient recombinant adenovirus vectors. Circ. Res. 72:1132-1138.

2. Lee, S. W., B. C. Trapnell, J. J. Rade, R. Virmani, and D. A. Dichek. 1993. In vivo adenoviral vector-mediated gene transfer into balloon-injured rat carotid arteries. Circ. Res. 73:797-807.

3. Guzman, R., P. Lemarchand, R. G. Crystal, S. E. Epstein, and T. Finkel. 1993. Efficient and selective adenovirus-mediated gene transfer into vascular neointima. Circulation. 88:2838-2848.

4. Rome, J. J., V. Shayani, M. Y. Flugelman, K. D. Newman, A. Farb, R. Virmani, and D. A. Dichek. 1994. Anatomic barriers influence the distribution of in vivo gene transfer into the arterial wall. Modeling with microscopic tracer particles and verification with a recombinant adenoviral vector. Arterioscler. Thromb. 14:148-161.

5. Willard, J. E., C. Landau, D. B. Glamann, D. Burns, M. E. Jessen, M. J. Pirwitz, R. D. Gerard, and R. S. Meidell. 1994. Genetic modification of the vessel wall. Comparison of surgical and catheter-based techniques for delivery of recombinant adenovirus. Circulation. 89:2190-2197.

6. Chen, S.-J., J. M. Wilson, and D. W. M. Muller. 1994. Adenovirus-mediated gene transfer of soluble vascular cell adhesion molecule to porcine interposition vein grafts. Circulation. 89:1922-1928.

7. March, K. L., I. Gradus-Pizlo, R. L. Wilensky, S. Yei, and B. C. Trapnell. 1994. Cardiovascular gene therapy using adenoviral vectors: distant transduction following local delivery using a porous balloon catheter. J. Am. Coll. Cardiol. 23:177a. (Abstr.)

8. Ohno, T., D. Gordon, H. San, V. J. Pompili, M. J. Imperiale, G. J. Nabel, and E. G. Nabel. 1994. Gene therapy for vascular smooth muscle cell proliferation after arterial injury. Science (Wash. DC). 265:781-784.

9. Steg, P. G., L. J. Feldman, J.-Y. Scoazec, O. Tahlil, J. J. Barry, S. Boulechfar, T. Ragot, J. M. Isner, and M. Perricaudet. 1994. Arterial gene transfer to rabbit endothelial and smooth muscle cells using percutaneous delivery of an adenoviral vector. Circulation. 90:1648-1656.

10. French, B. A., W. Mazur, N. M. Ali, R. S. Geske, J. P. Finnigan, G. P. Rodgers, R. Roberts, and A. E. Raizner. 1994. Percutaneous transluminal in vivo gene transfer by recombinant adenovirus in normal porcine coronary arteries, atherosclerotic arteries, and two models of coronary restenosis. Circulation. 90:2402-2413.

11. Nabel, E. G., G. Plautz, and G. J. Nabel. 1990. Site-specific gene expres- sion in vivo by direct gene transfer into the arterial wall. Science (Wash. DC) 249:1285-1288.

12. Flugelman, M. Y., M. T. Jaklitsch, K. D. Newman, W. Casscells, G. L. Brathauer, and D. A. Dichek. 1992. Low level in vivo gene transfer into the arterial wall through a perforated balloon catheter. Circulation. 85:1110-1117.

13. Lim, C. S., G. D. Chapman, J. B. Gammon, R. P. Mulhestein, R. S. Bauman, R. S. Stack, and J. L. Swain. 1991. Direct in vivo gene transfer into the coronary and peripheral vasculatures of the intact dog. Circulation. 83:578-583.

14. Leclerc, G., D. Gal, S. Takeshita, S. Nikol, L. Weir, and J. M. Isner. 1992. Percutaneous arterial gene transfer in a rabbit model. Efficiency in normal and balloon-dilated atherosclerotic arteries. J. Clin. Invest. 90:936-944.

15. Chapman, G. D., C. S. Lim, R. S. Gammon, S. C. Culp, J. S. Desper, R. P. Bauman, J. L. Swain, and R. S. Stack. 1992. Gene transfer into coronary arteries of intact animals with a percutaneous balloon catheter. Circ. Res. 71:2733.

16. Riessen, R., H. Rahimizadeh, S. Takeshita, D. Gal, J. J. Barry, and J. M. Isner. 1993. Successful vascular gene transfer using a hydrogel coated balloon angioplasty catheter. Hum. Gene Ther. 4:749-758.

17. Barinaga, M. 1994. Gene therapy for clogged arteries passes test in pigs Science (Wash. DC). 265:738.

18. Faxon, D. P., V. J. Weber, C. Haudenschild, S. B. Gottsman, W. A. McGovern, and T. J. Ryan. 1982. Acute effects of transluminal coronary angioplasty in three experimental models of atherosclerosis. Arteriosclerosis. 2:125133.

19. Muller, D. W., S. G. Ellis, and E. J. Topol. 1992. Experimental models of coronary artery restenosis. J. Am. Coll. Cardiol. 19:418-432.

20. Weidinger, F. F., J. M. McLenachan, M. I. Cybulsky, J. T. Fallon, N. K Hollenberg, J. P. Cooke, and P. Ganz. 1991. Hypercholesterolemia enhances macrophage recruitment and dysfunction of regenerated endothelium after balloon injury of the rabbit iliac artery. Circulation. 84:755-767.

21. Quantin, B., L. D. Stratford-Perricaudet, S. Tajbakhsh, and J.-L. Mandel. 1992. Adenovirus as an expression vector in muscle cells in vivo. Proc. Natl. Acad. Sci. USA. 89:2581-2584.

22. Stratford-Perricaudet, L. D., I. Makeh, M. Perricaudet, and P. Briand. 1992. Widespread long-term gene transfer to mouse skeletal muscles and heart. J. Clin. Invest. 90:626-630.

23. Rosenfeld, M. A., K. Yoshimura, B. C. Trapnell, K. Yoneyama, E. R. Rosenthal, W. Dalemans, M. Fukayama, J. Bargon, L. E. Stier, L. D. StratfordPerricaudet et al. 1992. In vivo transfer of the human cystic fibrosis transmembrane conductance regulator gene to the airway epithelium. Cell. 68:143-155.

24. Baumgartner, H. R., and A. Studer. 1963. Controlled over-dilatation of the abdominal aorta in normo- and hypercholesterolemic rabbits. Pathol. Microbiol. 26:129-148.

25. Riessen, R., and J. M. Isner. 1994. Prospects for site-specific delivery of pharmacologic and molecular therapies. J. Am. Coll. Cardiol. 23:1234-1244.

26. Losordo, D. W., K. Rosenfield, A. Pieczek, K. Baker, M. Harding, and J. M. Isner. 1992. How does angioplasty work? Serial analysis of human iliac arteries using intravascular ultrasound. Circulation. 86:1845-1858.

27. Sanes, J. R., J. L. R. Rubenstein, and J. F. Nicolas. 1986. Use of a recombinant retrovirus to study post-implantation cell lineage in mouse embryos. EMBO (Eur. Mol. Biol. Organ) J. 5:3133-3142.

28. Schreiber, E., P. Matthias, M. M. Müller, and W. Schaffner. 1989. Rapid detection of octamer binding proteins with mini-extracts, prepared from a small number of cells. Nucleic Acids Res. 17:6419.

29. Wallenstein, S., C. L. Zucker, and J. L. Fleiss. 1980. Some statistical methods useful in circulation research. Circ. Res. 47:1-9.

30. Block, P. C., K. L. Baugham, R. C. Pasternak, and J. T. Fallon. 1980. Transluminal angioplasty: correlation of morphologic and angiographic findings in an experimental model. Circulation. 61:778-785.

31. Schneider, M. D., and B. A. French. 1993. The advent of adenovirus Gene therapy for cardiovascular disease. Circulation. 88:1937-1942.

32. Epstein, S. E., E. Speir, E. F. Unger, R. J. Guzman, and T. Finkel. 1994. The basis of molecular strategies for treating coronary restenosis after angioplasty. J. Am. Coll. Cardiol. 23:1278-1288.

33. Chang, M., E. Barr, J. Seltzer, Y-Q. Jiang, G. J. Nabel, E. G. Nabel, M. S. Parmacek, and J. M. Leiden. 1994. Cytostatic gene therapy for vascular proliferative disorders with a constitutively active form of the retinoblastoma gene product. Circulation. 90:I-90. (Abstr.)

34. Isner, J. M., and L. J. Feldman. 1994. Gene therapy for arterial disease. Lancet. 314:1653-1654.

35. Ross, R. 1993. The pathogenesis of atherosclerosis: a perspective for the 1990s. Nature (Lond.). 362:801-809.

36. Akli, S., C. Caillaud, E. Vigne, L. D. Stratford-Perricaudet, L. Poenaru, M. Perricaudet, A. Kahn, and M. R. Peschanski. 1993. Transfer of a foreign gene into the brain using adenovirus vectors. Nature Genet. 3:224-228.

37. Engelhardt, J. F., Y. Yang, L. D. Stratford-Perricaudet, E. D. Allen, K. Kozarsky, M. Perricaudet, J. R. Yankaskas, and J. M. Wilson. 1993. Direct gene 
transfer of human bronchial epithelia of xenografts with E1-deleted adenoviruses. Nature Genet. 4:27-34.

38. Gao, L., E. Wagner, M. Cotten, S. Agarwal, C. Harris, M. Romer, L. Miller, P.-C. Hu, and D. Curiel. 1994. Direct in vivo gene transfer to airway epithelium employing adenovirus-polylysine-DNA complexes. Hum. Gene Ther. 4:17-24.

39. Le Gal La Salle, G., J. J. Robert, S. Berrard, V. Ridoux, L. D. StratfordPerricaudet, M. Perricaudet, and J. Mallet. 1993. An adenovirus vector for gene transfer into neurons and glia in the brain. Science (Wash. DC). 259:988-990.

40. Mastrangeli, A., C. Danel, M. A. Rosenfeld, L. D. Stratford-Perricaudet, M. Perricaudet, A. Pavirani, J.-P. Lecocq, and R. G. Crystal. 1993. Diversity of airway epithelial cell targets for in vivo recombinant adenovirus-mediated gene transfer. J. Clin. Invest. 91:225-234.

41. Ragot, T., N. Vincent, P. Chafey, E. Vigne, H. Gilgenkrantz, D. Couton, J. Cartaud, P. Briand, J.-C. Kaplan, M. Perricaudet, and A. Kahn. 1993. Efficient adenovirus-mediated transfer of a human minidystrophin gene to skeletal muscle of mdx mice. Nature. 361:647-650.

42. Rosenfeld, M. A., C.-S. Chu, P. Seth, C. Danel, T. Banks, K. Yoneyama, K. Yoshimura, and R. G. Crystal. 1994. Gene transfer to freshly isolated human respiratory epithelial cells in vitro using a replication-deficient adenovirus containing the human cystic fibrosis transmembrane conductance regulator cDNA. Hum. Gene Ther. 5:331-342.
43. Vincent, N., T. Ragot, H. Gilgenkrantz, D. Couton, P. Chafey, A. Grégoire, P. Briand, J.-C. Kaplan, A. Kahn, and M. Perricaudet. 1993. Long-term correction of mouse dystrophic degeneration by adenovirus-mediated transfer of a minidystrophin gene. Nature Genet. 5:130-134.

44. Kozarsky, K. F., D. R. McKinley, L. L. Austin, S. E. Raper, L. D. StratfordPerricaudet, and J. M. Wilson. 1994. In vivo correction of low-density lipoprotein receptor deficiency in the Watanabe heritable hyperlipidemic rabbit with recombinant adenoviruses. J. Biol. Chem. 269:13695-13702.

45. Barger, A. C., R. Beeuwkes, L. L. Lainey, and K. J. Silverman. 1984. Hypothesis: vasa-vasorum and neovascularization of human coronary arteries. $N$. Engl. J. Med. 310:175-177.

46. Schulick, A. H., K. D. Newman, and D. A. Dichek. 1994. A therapeutic window for in vivo adenoviral vector-mediated gene transfer. Circulation. 90:I516. (Abstr.)

47. March, K. L., J. E. Madison, and B. C. Trapnell. 1995. Pharmacokinetics of adenoviral-mediated gene delivery to vascular smooth muscle cells: Modulation by Poloxamer 407 and implications for cardiovascular gene therapy. Hum. Gene Ther. 6:41-53.

48. Pastore, C., L. J. Feldman, M. Perricaudet, and P. G. Steg. 1994. Intraluminal delivery of a pluronic gel enhances adenovirus-mediated arterial gene transfer: a morphometric study. Circulation. 90:I-517. (Abstr.) 